\title{
Análisis comparativo de las exportaciones e importaciones 2013-2016 al implementar la nueva matriz productiva ecuatoriana
}

\section{Comparative analysis of exports and imports 2013-2016 in implementing the new ecuadorian productive matrix}

\author{
Puglla, Rosa*, Andrade Mendoza, David M. y Vanegas Coello, Juliana L. \\ ${ }^{1}$ Universidad Católica de Cuenca, Sede Macas. Ecuador \\ *rpugllao@ucacue.edu.ec
}

\begin{abstract}
Resumen
Este trabajo se centró en una investigación enfocada en la comparación de las exportaciones e importaciones que se realizaron entre los periodos 2013 y 2016. El objetivo de este artículo es entregar un análisis que demuestre el impacto que ha tenido la implementación de la nueva matriz productiva en la balanza comercial del país, en los ya mencionados años. El Ecuador desde sus comienzos ha sido un país exportador de materias primas, mas no de productos ya elaborados o finales, mientras que en sus importaciones opta por productos con mayor calidad, ya que su costo es más bajo, por lo que los consumidores los prefieren más que a los propios productos, por esta razón el gobierno planteó el cambio de la matriz productiva con el propósito de transformar la especialización de la producción ecuatoriana otorgándole un valor agregado. Este estudio se desarrolló con un enfoque investigativo mixto, es decir; cualitativo y cuantitativo, cualitativo debido a que se estudiaron las conceptualizaciones de las exportaciones e importaciones. Cuantitativo por los datos estadísticos estudiados, específicamente de la balanza comercial en los años que son objeto de estudio para determinar si estos años presentan déficit y superávit. La información se obtuvo del informe del Banco Central del Ecuador (BCE). Se concluye que existe una pequeña variación en cuanto a las exportaciones de país, las cuales crecieron en comparación con el 2013, por lo que se entiende que las medidas tomadas por el gobierno en la especialización de nuestra producción han traído superávit a la Balanza Comercial.
\end{abstract}

Palabras clave: Matriz productiva, Balanza Comercial, exportaciones, importaciones..

\begin{abstract}
This work focused on a research focused on the comparison of exports and imports that were made between the periods 2013 and 2016. The objective of this article is to provide an analysis that demonstrates the impact that the implementation of the new productive matrix has had on the trade balance of the country, in the aforementioned years. Ecuador since its inception has been an exporter of raw materials, but not already finished or finished products, while in its imports opts for products with higher quality, since its cost is lower, so consumers prefer them more than the products themselves, for this reason the government proposed the change of the productive matrix with the purpose of transforming the specialization of the Ecuadorian production, giving it an added value. This study was developed with a mixed investigative approach, ie; qualitative and quantitative, qualitative because the concepts of exports and imports were studied. Quantitative for the statistical data studied, specifically the trade balance in the years under study to determine if these years present a deficit and surplus. The information was obtained from the report of the Central Bank of Ecuador (ECB). It is concluded that there is a small variation in terms of the country's exports, which grew in comparison with 2013, so it is understood that the measures taken by the government in the specialization of our production have brought surplus to the Commercial Balance.
\end{abstract}

Key words: Productive Matrix, Trade Balance, exports, imports..

\section{Introducción}

Según la estrategia para el cambio de la matriz productiva propuesta en el 2015 por la Vicepresidencia de la República del Ecuador, el país necesita romper con la inercia que lo mantiene prisionero de una estructura productiva anclada a un pequeñísimo número de precios internacionales. Para ello, el Estado debe jugar un papel importante, no solo para proveer los bienes y servicios públicos que desencadenen nuevas inversiones, sino para identificar y eliminar los procesos que dificultan el desarrollo de actividades, sectores o cadenas productivas de alto potencial; así como para generar políticas, programas y planes de fomento para su impulso, y la institucionalidad necesaria para sostener este proceso de transformación productiva.

La matriz productiva es el manera de organización de un país, para producir ciertos bienes y servicios con un 
precio competitivo, "no se limita únicamente a los procesos estrictamente técnicos o económicos, sino que también tiene que ver con todo el conjunto de interacciones entre los distintos actores sociales que utilizan los recursos que tienen a su disposición para llevar adelante las actividades productivas" (SENPLADES, 2012).

El Folleto sobre la Transformación de la Matriz productiva (2012), nos menciona lo siguiente:

El Gobierno Nacional plantea transformar el patrón de especialización de la economía ecuatoriana y lograr una inserción estratégica y soberana en el mundo, lo que nos permitirá:

- Contar con nuevos esquemas de generación, distribución y redistribución de la riqueza

- Reducir la vulnerabilidad de la economía ecuatoriana

- Eliminar las inequidades territoriales

- Incorporar a los actores que históricamente han sido excluidos del esquema de desarrollo de mercado

La implementación del matiz productiva provoco el paso del pensamiento de primario exportador a uno de especialización de los productos y de servicios basados en una economía del conocimiento y con valor agregado. Los ejes para la transformación de la matriz productiva según el Folleto sobre la Transformación de la Matriz productiva (2012) son:

1) Diversificación productiva basada en el desarrollo de industrias estratégicas-refinería, astillero, petroquímica, metalurgia y siderúrgica y en el establecimiento de nuevas actividades productivas-maricultura, biocombustibles, productos forestales de madera que amplíen la oferta de productos ecuatorianos y reduzcan la dependencia del país.

2) Agregación de valor en la producción existente mediante la incorporación de tecnología y conocimiento en los actuales procesos productivos de biotecnología (bioquímica y biomedicina), servicios ambientales y energías renovables.

3) Sustitución selectiva de importaciones con bienes y servicios que ya producimos actualmente y que seríamos capaces de sustituir en el corto plazo: industria farmacéutica, tecnología (software, hardware y servicios informáticos) y metalmecánica.

4) Fomento a las exportaciones de productos nuevos, provenientes de actores nuevos particularmente de la economía popular y solidaria-, o que incluyan mayor valor agregado alimentos frescos y procesados, confecciones y calzado, turismo. Con el fomento a las exportaciones buscamos también diversificar y ampliar los destinos internacionales de nuestros productos.

La política de un desarrollo selectivo de la industria para el cambio del patrón de especialización productiva tenía como meta incrementar el peso de la manufactura en la generación del valor agregado nacional, mediantes estrategias o propuestas que dinamicen este sector.

Los resultados de esta estrategia muestran que "en el año 2007 la industria manufacturera contribuyo con el
$13.7 \%$ al producto interno bruto y para el año 2013 esta participación descendió al 12.4\%". (Villavicencio, 2016). Según la información esta diminución se debió al freno que tuvo la inversión del sector manufacturero puesto que en el mismo periodo pasó del $11.7 \%$ de la inversión total al $10.4 \%$. Más revelador aun es el comportamiento de la inversión privada en maquinaria y equipo cuya inversión disminuyó del $82.5 \%$ en 2007 al $65.8 \%$ en el 2013. (Villavicencio, 2016)

La crisis económica provoco que esta tendencia de decrecimiento continuara, ya que para el 2016 el sector manufacturero representaba el $10 \%$ del PIB, por estos resultado se observó que el fortalecimiento del sector productivo con mayor valor agregado no estaba funcionado como el gobierno lo esperaba.

En relación al PIB y para el mismo periodo, las exportaciones de la manufactura representaron el $10.4 \%$ en el 2007 y el $6 \%$ en el 2013, es decir; no se produjo ninguna diversificación de las exportaciones hacia productos con un mayor valor agregado.

De acuerdo al plan de desarrollo, la sustitución de importaciones se enfoca en los sectores que cumplan con las siguientes características generales: secundario-terciarios, generadores de valor, desarrollo de infraestructura y capacidades estratégicas para el sector en cuestión, empleo de mano de obra calificada, desarrollo de tecnología y capacidades humanas especializadas. Según (Villavicencio, 2016) "el indicador que refleja el fracaso más evidente de esta estrategia es el déficit comercial de la balanza comercial no petrolera por el incremento explosivo de las importaciones, sobre todo de bienes de consumo". Puesto que "en el año 2013, este déficit llego a superar la suma de 9.000 millones de dólares." Según el autor esta situación obligó al Gobierno a restringir las importaciones mediante un sistema de salvaguardias con el fin de detener el flujo de divisas que ponían en riesgo el sistema mismo de dolarización de la economía.

Para entender mejor algunos conceptos de este artículo a continuación se describirá sus definiciones.

Según Enrique Cornejo Ramírez (1996), define el comercio internacional como"... el intercambio de bienes y servicios entre residentes de diferentes países".

La exportación es la "Transferencia de la propiedad de los bienes o prestación de los servicios producidos por una economía residente a otra no residente. Venta de productos nacionales (bienes y servicios) a un mercado extranjero.”(Glosario de Términos Económicos)

La importación es la "Transferencia de la propiedad de los bienes o prestación de los servicios producidos en el exterior a residentes de una economía. Compra de productos (bienes y servicios) a un mercado extranjero."(Glosario de Términos Económicos)

La balanza comercial o de exportaciones netas, es la diferencia entre el valor monetario de las exportaciones e importaciones en la economía de un país durante un determinado período, medidos en la moneda de esa economía. 
Un balance positivo se conoce como un superávit en la balanza comercial, que consiste en exportar más de lo que se importa mientras que un balance negativo se conoce como un déficit comercial.

\section{Sector no petrolero}

Según el catedrático de economía Patricio Almeida "El valor agregado no petrolero refleja los productos de consumo final o de exportación generados por la industria o los servicios, excepto producción y refinación de petróleo"

\section{Sector Petrolero}

La industria petrolera incluye procesos globales de exploración, extracción, refino, transporte (frecuentemente a través de buques petroleros y oleoductos) y mercadotecnia de productos del petróleo.

\section{Contextualización}

Ecuador (nombre oficial: República del Ecuador) es un país situado en la parte noroeste de América del Sur. Ecuador limita al norte con Colombia, al sur y al este con Perú y al oeste con el océano Pacífico. El país tiene una extensión de $283.561 \mathrm{~km}^{2}$. Además del territorio continental, Ecuador está formada por el archipiélago de Colón, aparte de otras cercanas al continente, como Puná, Santay, y la Isla de la Plata.

Ecuador se encuentra sobre la línea ecuatorial terrestre por lo cual su territorio se encuentra en ambos hemisferios. Comprende dos espacios distantes entre sí: el territorio continental al noroeste de América del Sur con algunas islas adyacentes a la costa $\mathrm{y}$, el archipiélago o provincia insular de Galápagos, que se encuentra a 1000 kilómetros de distancia del litoral ecuatoriano en el Océano Pacífico.

Tendencias generales del clima para cada región de Ecuador:

El Oriente: Por lo general tiene un clima cálido, húmedo y lluvioso. La temperatura promedio varía entre los 23 y los 26 grados Celcius (72 a 80 grados Fahrentheit). El período más seco va de noviembre a febrero, pero varía según las subregiones. (OEC, 2017)

La Sierra: En Ecuador el clima es menos cálido de lo que muchos pudieran esperar. Particularmente en los Andes las temperaturas varían en dependencia de la altitud y la época del año. En Quito estas oscilan entre los 7, en la noche, y los 26 grados Celcius en el día (55 a 78 grados Fahrentheit), con una temperatura promedio de 15 grados Celcius (64 grados Fahrentheit). (OEC, 2017)

La Costa: Aquí el clima es muy cálido con temperaturas que oscilan entre 25 y 31 grados Celcius (76 a 90 grados Fahrentheit) durante todo el año. La estación lluviosa, que va de diciembre a mayo, es cálida y muy húmeda. La estación seca, realmente no lo es tanto. (OEC, 2017)

Las Islas Galápagos disfrutan de un clima seco durante todo el año con una temperatura promedio de 28 grados Celcius (85 grados Fahrentheit).

El Ecuador es la $69^{\circ}$ mayor economía de exportación en el mundo y la economía más compleja $96^{\circ}$ de acuerdo con el Índice de Complejidad Económica (ECI). En 2015, el Ecuador exportó \$19,5 Miles de millones e importó $\$ 21,1$ Miles de millones, dando como resultado un saldo comercial negativo de \$1,64 Miles de millones. En 2015 el PIB de Ecuador fue de $\$ 100$ Miles de millones y su PIB per cápita fue de \$11,5 Miles. (OEC, 2017)

Las principales exportaciones de Ecuador son Petróleo Crudo(\$6,55 Miles de millones), Plátanos (\$3,27 Miles de millones), Crustáceos (\$2,27 Miles de millones), Pescado Procesado (\$942 Millones) y Flores Cortadas (\$760 Millones), de acuerdo a la clasificación del Sistema Harmonizado (HS). Sus principales importaciones son Refinado de Petróleo (\$2,08 Miles de millones), Alquitrán de aceite (\$1,48 Miles de millones), Medicamentos envasados (\$755 Millones), Coches (\$530 Millones) y Camiones de reparto (\$382 Millones). (OEC, 2017)

Los principales destinos de las exportaciones de Ecuador son los Estados Unidos (\$7,23 Miles de millones), Chile (\$1,09 Miles de millones), el Perú (\$988 Millones), Colombia (\$792 Millones) y Rusia (\$782 Millones). Los principales orígenes de sus importaciones son los Estados Unidos (\$4,95 Miles de millones), China (\$4,03 Miles de millones), Colombia (\$1,48 Miles de millones), Corea del Sur (\$815 Millones) y Brasil (\$725 Millones). (OEC, 2017)

\section{Metodología}

El enfoque investigativo utilizado ha sido el mixto, desde lo cualitativo se estudiaron las características y cualidades del mercado en cuanto a la parte petrolera y no petrolera. En relación a lo cuantitativo se estudiaron datos que representan cifras relacionadas con: exportaciones petroleras, no petroleras, importaciones, valor monetario, déficit, superávit etc., obtenidos por el Banco Central del Ecuador.

Para este estudio se utilizaron varias metodologías de la investigación científica a partir de que la misma se define como la serie de pasos que conducen a la búsqueda de conocimientos mediante la aplicación de métodos y técnicas científicas.

Exploratoria: Son las investigaciones que pretenden dar una visión general de tipo aproximativo respecto a una determinada realidad, en este caso el tema elegido ha sido poco explorado y reconocido, razón por la cual inicialmente se declara como un estudio exploratorio.

Descriptivo: El objeto de esta investigación descriptiva consiste en describir y evaluar ciertas características de una situación particular relacionada con las importaciones y exportaciones en el ecuador y su comportamiento en los años que se analizan que corresponden a la implementación de la nueva matriz productiva, para descubrir si las variables están relacionadas entre sí.

Explicativa: La investigación se centra en determinar los orígenes o las causas de un determinado conjunto de fenómenos que intervienen en el objeto de estudio, donde el propósito es conocer por que suceden ciertos hechos a través de la delimitación de las relaciones causales existentes o, al menos, de las condiciones en que ellas producen. 
Tabla 1

Balanza Comercial Toneladas métricas en miles y valor USD FOB en millones

\begin{tabular}{|c|c|c|c|c|c|c|c|c|c|c|}
\hline & \multicolumn{2}{|c|}{ Ene - Dic 2010} & \multicolumn{2}{|c|}{ Ene - Dic 2011} & \multicolumn{2}{|c|}{ Ene - Dic 2012} & \multicolumn{2}{|c|}{ Ene - Dic 2013} & \multicolumn{2}{|c|}{ Variación } \\
\hline & & Valor & & Valor & & Valor & & Valor & & Valor \\
\hline Exportaciones totales & 26,628 & $17,489.93$ & 27,311 & $22,322.35$ & 27,922 & $23,764.76$ & 29,416 & $24,957.65$ & $5.351 \%$ & $5.0 \%$ \\
\hline No petroleras & 7,678 & $7,816.7$ & 8,543 & $9,377.5$ & 8,284 & $9,972.8$ & 8,764 & $10,849.9$ & $5.8 \%$ & $8.8 \%$ \\
\hline Importaciones totales & 13,716 & $19,468.7$ & 14,474 & $23,151.9$ & 14,283 & $24,205.4$ & 15,767 & $26,041.6$ & $10.4 \%$ & $7.6 \%$ \\
\hline Bienes de consumo & 1,052 & $4,116.5$ & 1,144 & $4,742.9$ & 1,053 & $4,825.8$ & 998 & $5,002.1$ & $-5.2 \%$ & $3.7 \%$ \\
\hline Bienes de capital & 497 & $5,129.1$ & 531 & $5,844.6$ & 543 & $6,418.1$ & 579 & $6,778.0$ & $6.6 \%$ & $5.6 \%$ \\
\hline Combustibles y Lubricantes & 5,639 & $4,042.8$ & 5,245 & $5,086.5$ & 5,301 & $5,441.3$ & 6,156 & $6,080.2$ & $16.1 \%$ & $11.7 \%$ \\
\hline Diversos & 11.9 & 75.6 & 5.1 & 40.7 & 4.4 & 42.2 & 6.4 & 61.7 & $47.1 \%$ & $46.1 \%$ \\
\hline Ajustes (4) & & 189.9 & & 63.7 & & 23.8 & & 62.1 & & $161.1 \%$ \\
\hline Balanza Comercial - Total & & $-1,978.7$ & & -829.5 & & -440.6 & & $-1,084.0$ & & \\
\hline
\end{tabular}

Fuente: (BancoCentralDelEcuador, 2013)SENAE, SHE, EP Petroecuador.

Entorno: El estudio se realizará en Ecuador.

Análisis estadístico: Se ha empleado la Estadística Descriptiva con el método de análisis porcentual y numérico, con lo cual se obtuvo los indicadores de la Balanza Comercial, con la comparativa de datos obtenidos en diferentes años por (Banco Central del Ecuado, 2014) SENAE, SHE y EP Petroecuador, se dio como resultado una comparativa final entre 2013 y 2016 para poder analizar el cambio existente en este periodo de tiempo de 4 años.

\section{Resultados}

Luego de Investigar y obtener la información de la balanza comercial de los periodos entre 2013 y 2016, se procedió con la comparativa entre cada año, el cual es el principal objetivo de este trabajo de investigación sobre la Balanza Comercial, estos datos ayudan a ver cómo eran las exportaciones e importaciones antes y después del implemento de la Matriz Productiva, la misma que es una propuesta a largo plazo, y no algo que se puede implementar de la noche a la mañana, por lo que aún no se transforma en su totalidad, pero algunos cambios ya son visibles.

En tabla 1 se observa la evolución de la balanza comercial desde el año 2010, podemos apreciar que en el año 2010 tenemos exportaciones por Toneladas Métricas (TM) de 26.628 millones con una valor de 17.489,93 millones de dólares, mientras que las importaciones pese a ser menores puesto que son de 13.716 millones de TM tienen un valor mayor a lo exportando ya que este es de 19.468,7 millones de dólares, dando como resultado una Balanza

Tabla 2

Balanza Comercial Toneladas métricas en miles y valor USD FOB en millones

\begin{tabular}{|c|c|c|c|c|c|c|c|c|c|c|}
\hline & \multicolumn{2}{|c|}{ Ene - Dic 2011} & \multicolumn{2}{|c|}{ Ene - Dic 2012} & \multicolumn{2}{|c|}{ Ene - Dic 2013} & \multicolumn{2}{|c|}{ Ene - Dic 2014} & \multicolumn{2}{|c|}{ Variación 2014 / 2013} \\
\hline & & Valor USD & & Valor USD & & Valor USD & & Valor USD & & Valor USD \\
\hline & TM & $\mathrm{FOB}$ & TM & FOB & TM & FOB & TM & FOB & TM & FOB \\
\hline Exportaciones totales & 27,311 & $22,322.4$ & 27,922 & $23,764.8$ & 29,441 & $24,847.8$ & 31,402 & $25,732.3$ & $6.7 \%$ & $3.6 \%$ \\
\hline Petroleras & $18,767.7$ & $12,944.9$ & $19,637.6$ & $13,792.0$ & $20,651.9$ & $14,107.7$ & $22,092.3$ & $13,302.5$ & $7.0 \%$ & $-5.7 \%$ \\
\hline No petrolenas & $8,543.3$ & $9,377.5$ & $8,284.1$ & $9,972.8$ & $8,788.8$ & $10,740.1$ & $9,310.0$ & $12,429.8$ & $5.9 \%$ & $15.7 \%$ \\
\hline Importaciones totales & 14,474 & $23,151.9$ & 14,283 & $24,205.4$ & 15,620 & $25,888.8$ & 17,300 & $26,459.3$ & $10.8 \%$ & $2.2 \%$ \\
\hline Bienes de consumo & 1,144 & $4,742.9$ & 1,053 & $4,825.8$ & 998 & $5,002.1$ & 1,111 & $5,020.1$ & $11.3 \%$ & $0.4 \%$ \\
\hline Trúfico Postal Internacionaly Correos Rápidos (2) & n.d. & 142.3 & n.d. & 163.3 & 4.8 & 228.3 & 4.3 & 212.3 & $-10.5 \%$ & $-7.0 \%$ \\
\hline Materias primas & 7,549 & $7,231.0$ & 7,381 & $7,290.9$ & 8,028 & $7,829.2$ & 8,619 & $8,079.7$ & $7.4 \%$ & $3.2 \%$ \\
\hline Bienes de capital & 531 & $5,844.6$ & 543 & $6,418.1$ & 579 & $6,778.0$ & 581 & $6,648.1$ & $0.4 \%$ & $-1.9 \%$ \\
\hline Combustibles y Lubricantes & 5,245 & $5,0.86 .5$ & 5,301 & $5,441.3$ & 6,009 & $5,927.4$ & 6,985 & $6,417.4$ & $16.2 \%$ & $8.3 \%$ \\
\hline Diversos & 5.1 & 40.7 & 4.4 & 42.2 & 6.4 & 61.7 & 5.3 & 55.7 & $-16.8 \%$ & $-9.8 \%$ \\
\hline Ajustes (3) & & 63.7 & & 24 & & 62.1 & & 26.1 & & $-58.0 \%$ \\
\hline Balanza Comercial - Total & & -829.5 & & -440.6 & & $-1,041.0$ & & -727.0 & & $30.2 \%$ \\
\hline Bal. Comenial-Petrolera & & $7,858.3$ & & $8,350.7$ & & $8,180.3$ & & $6,885.1$ & & $-15.8 \%$ \\
\hline Bal. Comenial-No petrolera & & $-8,687.8$ & & $-8,791.3$ & & $-9,221.3$ & & $-7,612.1$ & & $17.5 \%$ \\
\hline
\end{tabular}

Fuente: (BancoCentralDelEcuador, 2013)SENAE, SHE, EP Petroecuador. 
Tabla 3

Balanza Comercial Toneladas métricas en miles y valor USD FOB en millones

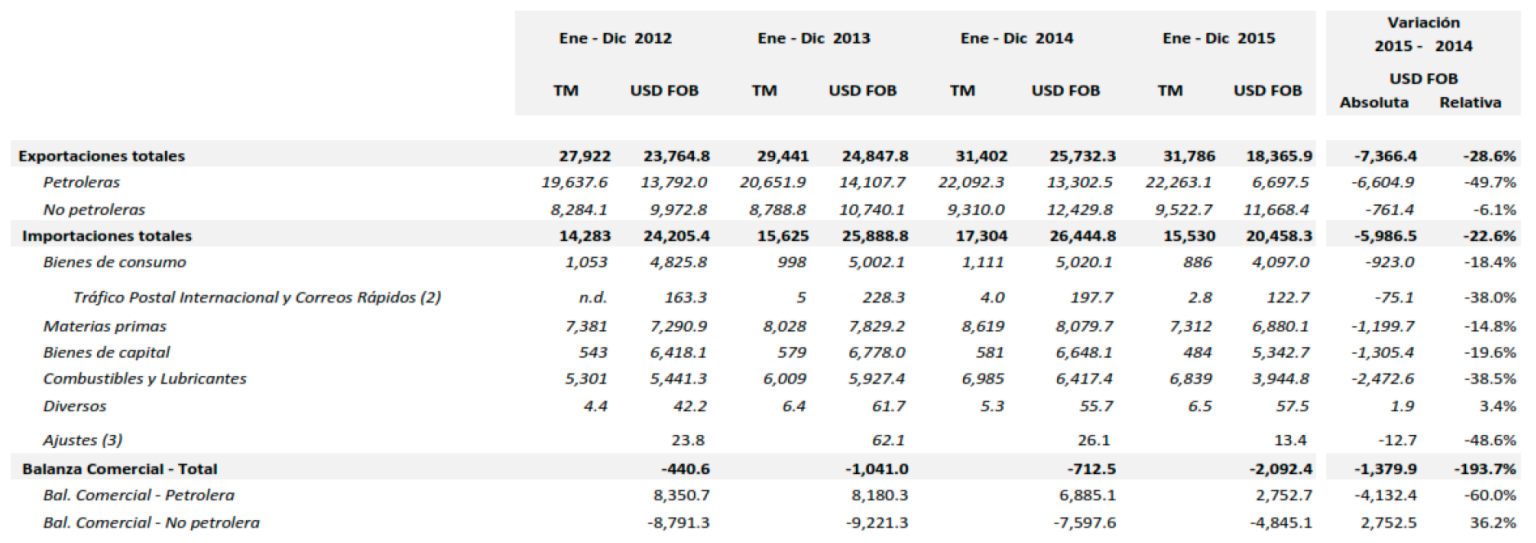

Fuente: (BancoCentralDelEcuador, 2015) SENAE, SHE, EP Petroecuador.

Comercial Negativa de $-1.978,7$ millones de dólares, nada de esto cambio en los consiguientes años, en el 2011 una balanza comercial negativa de -829,5 USD FOB, 2012 440,6 USD FOB y en el 2013 vemos que las Exportaciones han aumentado a 29.416 TM con un valor de 24957.65 USD FOB pero las importaciones de ese mismo año también aumentaron a 15.767 TM con un valor de 26.041,6 USD FOB dando nuevamente una Balanza Comercial Negativa para el País con -1.084,0 Millones de Dólares.

Siempre se observa que las cantidades exportadas en TM son mayores a las importaciones, pero el valor que tienen las importaciones siempre supera a lo que obtenemos exportando, lo cual es una muestra clara del porqué del implemento de la nueva matriz productiva, ya que esto es una señal de que lo que exportamos es casi en su mayoría materia prima, mientras que lo importado es productos elaborados, se deduce entonces que su cantidad pese a ser casi siempre la mitad de lo exportado excede en su valor.

En tabla 2 podemos analizar la variación existente para el año 2014, en este vemos que las Exportaciones son de $31.402 \mathrm{TM}$ con un valor de 25.732,3 y las importaciones 17.300 TM con un valor de 26.459,3 millones de dólares, en cuanto a Exportaciones las TM han aumentado un 6,7 \% y su valor también con un 3,6\%, esto no basta para mejorar la Balanza Comercial puesto que las importaciones también aumentaron un $10,8 \%$ en TM y $2,2 \%$ en su valor, dando nuevamente una balanza comercial negativa de $-727,0 \mathrm{mi}-$ llones de dólares.

En los datos obtenidos para el 2015 (tabla 3) se aprecia una variación alarmante ya que sus Exportaciones aunque incrementaron su valor disminuye a 18.365,9 millones de dólares y las importaciones aunque hayan disminuido aún siguen siendo mayores que las exportaciones, dando una balanza comercial negativa de -2.092,4 millones de dólares, cabe recalcar que he aquí cuando el precio del barril del petróleo decayó hasta los 38 dólares por barril, lo cual fue un durísimo golpe para la economía del país, conllevando esto a una balanza comercial negativa nunca vista en los últimos 5 años.

Para el año 2016 la Balanza Comercial del Ecuador tiene un giro radical (tabla 4), esto gracias a varias restricciones que puso el estado y otras medidas más:

\section{Salvaguardias}

Las salvaguardias (valor adicional al arancel) cambiarias entraron en vigencia desde el 5 de enero para productos provenientes de Colombia ( $21 \%$ ) y Perú (7\% ). Luego, en marzo se reemplaza esta medida con la aplicación de sobretasas globales al $32 \%$ de las importaciones ecuatorianas (2.800 partidas arancelarias), por un periodo de 15 meses, desde el $5 \%, 15 \%, 25 \%$ hasta el $45 \%$ según el tipo de productos. (Universo, 2015)

Tasas a viajeros Para frenar las compras en la frontera, ante el continuo desplazamiento de ecuatorianos para adquirir productos a más bajo precio, el Comité de Comercio Exterior (Comex) resuelve en septiembre del 2015 ampliar el cobro de las sobretasas o salvaguardia a los bienes tributables que acompañen a los viajeros, tanto vía terrestre como aérea. (Universo, 2015) El cobro consiste en un valor adicional a los aranceles y se aplica a alrededor del $30 \%$ de los artículos que Ecuador importa. Con la medida, vigente desde el 18 de septiembre del 2015, decayó la compra en la frontera con Colombia, por parte de ecuatorianos. (El Universo, 2015)

En este año vemos como las Exportaciones tienen un total de 31.942,3 TM con un valor de 16.797,7 millones de dólares mientras que las importaciones disminuyen a 13686.1 TM con un valor de 15.550,6 millones de dólares, esto nos da una Balanza Comercial Positiva de 1.247 millones de dólares por primera vez desde el 2010, lo cual nos indica que las medidas tomadas por el gobierno son acertadas, y han ayudado a mejorar la balanza comercial. 
Tabla 4

Balanza Comercial Toneladas métricas en miles y valor USD FOB en millones

\begin{tabular}{|c|c|c|c|c|c|c|c|c|c|c|}
\hline & \multicolumn{2}{|c|}{ Ene - Dic 2013} & \multicolumn{2}{|c|}{ Ene - Dic 2014} & \multicolumn{2}{|c|}{ Ene - Dic 2015} & \multicolumn{2}{|c|}{ Ene - Dic 2016} & \multirow{2}{*}{\multicolumn{2}{|c|}{$\begin{array}{c}\text { Variación } \\
2016-2015 \\
\text { USD FOB }\end{array}$}} \\
\hline & TM & USD FOB & тм & USD FOB & TM & USD FOB & TM & USD FOB & & \\
\hline Exportaciones totales & $29,252.8$ & $24,750.9$ & $31,407.2$ & $25,724.4$ & $31,679.0$ & $18,330.6$ & $31,942.3$ & $16,797.7$ & $-1,532.9$ & $-8.4 \%$ \\
\hline Petroleras & $20,651.5$ & $14,107.4$ & $22,057.0$ & $13,275.9$ & $22,156.3$ & $6,660.3$ & $22,079.4$ & $5,459.2$ & $-1,201.2$ & $-18.0 \%$ \\
\hline No petroleras & $8,601.3$ & $10,643.5$ & $9,350.2$ & $12,448.6$ & $9,522.7$ & $11,670.3$ & $9,863.0$ & $11,338.5$ & -331.8 & $-2.8 \%$ \\
\hline Importaciones totales & $15,625.9$ & $25,825.9$ & $17,221.1$ & $26,447.6$ & $15,544.2$ & $20,460.2$ & $13,686.1$ & $15,550.6$ & $-4,909.6$ & $-24.0 \%$ \\
\hline Bienes de consumo & 990.9 & $4,957.1$ & $1,076.3$ & $4,990.2$ & 885.2 & $4,096.1$ & 747.5 & $3,242.5$ & -853.6 & $-20.8 \%$ \\
\hline Tráfico Postal Internacional y Correos Rápidos (2) & 4.8 & 228.3 & 4.0 & 197.7 & 2.8 & 122.7 & 3.1 & 127.1 & 4.5 & $3.7 \%$ \\
\hline Materias primas & $8,033.4$ & $7,823.5$ & $8,567.9$ & $8,076.0$ & $7,311.1$ & $6,878.0$ & $6,850.9$ & $5,687.7$ & $-1,190.3$ & $-17.3 \%$ \\
\hline Bienes de capital & 581.8 & $6,766.8$ & 582.0 & $6,684.6$ & 483.7 & $5,342.4$ & 365.0 & $3,941.2$ & $-1,401.2$ & $-26.2 \%$ \\
\hline Combustibles y Lubricantes & $6,008.7$ & $5,927.2$ & $6,985.5$ & $6,417.3$ & $6,854.9$ & $3,950.1$ & $5,713.5$ & $2,490.4$ & $-1,459.7$ & $-37.0 \%$ \\
\hline Diversos & 6.4 & 61.1 & 5.3 & 55.6 & 6.5 & 57.5 & 6.0 & 56.2 & -1.3 & $-2.3 \%$ \\
\hline Ajustes (3) & & 62.1 & & 26.1 & & 13.43 & & 5.5 & & $100.0 \%$ \\
\hline Balanza Comercial - Total & & $-1,075.0$ & & -723.2 & & $-2,129.6$ & & $1,247.0$ & $3,376.7$ & $158.6 \%$ \\
\hline Bal. Comercial-Petrolera & & $8,237.4$ & & $6,917.1$ & & $2,757.0$ & & $2,969.1$ & 212.1 & $7.7 \%$ \\
\hline Exportaciones petroleras & & $14,107.4$ & & $13,275.9$ & & $6,660.3$ & & $5,459.2$ & $-1,201.2$ & $-18.0 \%$ \\
\hline Importaciones petroleras & & $5,870.0$ & & $6,358.8$ & & $3,903.4$ & & $2,490.1$ & $-1,413.3$ & $-36.2 \%$ \\
\hline Bal. Comercial - No petrolera & & $-9,312.4$ & & $-7,640.2$ & & $-4,886.6$ & & $-1,722.0$ & 3,164.6 & $64.8 \%$ \\
\hline Exportaciones no petroleras & & $10,643.5$ & & $12,448.6$ & & $11,670.3$ & & $11,338.5$ & -331.8 & $-2.8 \%$ \\
\hline Importaciones no petroleras & & $19,956.0$ & & $20,088.8$ & & $16,556.9$ & & $13,060.5$ & $-3,496.4$ & $-21.1 \%$ \\
\hline
\end{tabular}

Fuente: (BancoCentralDelEcuador, 2015) SENAE, SHE, EP Petroecuador.

\section{Conclusiones y Discusión}

Según los resultados obtenidos con los datos históricos se concluye que las actividades que más nos han aportado a la economía del país son las que provienen del petróleo, esto sucedió hasta el año 2015 donde las exportaciones bajaron a gran magnitud tanto que, del 2014 de un valor de 11.705,6 millones bajo a 5.942,2 millones en las exportaciones petroleras, esto sin duda se dio por el bajo precio del petróleo, en este año el precio del petróleo de 90,9 bajo a 44,3 dólares. Por este motivo el gobierno estableció políticas para proteger la producción nacional del efecto negativo de la caída del precio del petróleo, tratando de incrementar el sector no petrolero, es decir incentivando nuestra producción, para que los ciudadanos consuman y valoren los productos hechos en Ecuador.

Entre los años 2013 y 2015 el incremento de las importaciones provoco un déficit de la balanza comercial, sin duda esto se dio como respuesta a la gran debilidad de la estructura productiva del país. En 2013 el petróleo y sus derivados representan en el $57 \%$ del total de exportaciones, confirmando una vez más que el sistema de especialización del país está centrada en un solo conjunto de productos.

Las exportaciones durante el 2013 fue de 24.957,6 millones, de este valor $14.107,7$ millones representó las ventas de petróleo, las exportaciones no petroleras representó 10.849,9 millones, las tradicionales fueron de 5187,9 millones y las no tradicionales de 5662,1 millones, en este año la participación de las exportaciones no petroleras tradicionales y no tradicionales fueron de $47,8 \%$ y $52,2 \%$ respectivamente.

Dentro de las exportaciones no petroleras, los principales productos fueron banano y plátano con el 21,9\%, camarón con el 16,6\%, enlatados de pescado con el 12,5\%, flores naturales con el 7,7 \%, productos mineros el 5,1\%, El cacao y elaborados el 4,9\%.

Las importaciones en el año 2013 fueron de 26.041,6 millones de los cuales la participación de la compra de bienes de consumo fue de $20,1 \%$, las materias primas el $30,1 \%$ y los bienes de capital de $26 \%$ del total de importaciones.

En el 2016 las exportaciones petroleras fueron de 5459,2 millones del total de exportaciones los cuales fueron de $16.797,7$ millones.

Las exportaciones no petroleras fueron de 11.338,5 millones y también tuvieron un incremento en la cantidad de toneladas métricas pasando del 2013 de 8600 uno a 9863 en el 2016, en lo que se puede observar que en ese lapso de tiempo hubo una gran incentivación a las exportaciones no petroleras.

También se observa que las exportaciones petroleras disminuyeron en el 2016 en comparación con el periodo del 2013, esto debido a la crisis por la caída del precio del petróleo que afectó a las exportaciones de crudo, mientras que las toneladas métricas aumentaron de 20.652 a 22.079 .

Las exportaciones no petroleras aumentaron en el 2016 a 6457,3 millones y las no tradicionales disminuyeron a 4881,2 millones comparándolos con el periodo 2013, en este sentido se observa que la participación de las exportaciones no petroleras tradicionales y no tradicionales fueron de $56,9 \%$ y $43,1 \%$ respectivamente.

En el 2016 los productos que más exportaciones han tenido son el banano y plátano con el $24 \%$, en el sector camarotero fue de $22,8 \%$, el cacao y elaborados el $6,6 \%$, enlatados de pescado el $8 \%$, las flores naturales con el $7,1 \%$ del total de exportaciones no petroleras.

Analizando los resultados se entiende que la estrategia 
del cambio de la matriz productiva está logrando pequeños cambios en las exportaciones e importaciones del país, la balanza comercial no petrolera ha reducido a gran magnitud su déficit donde en 2013 era de -9.312,4 millones en el 2016 pasó a -1.722 millones, esto muestra que las medidas que el gobierno tomó para proteger la producción nacional contribuyeron para que el superávit del 2016 de 1.247 millones se cumpliera, con esto se redujo las importaciones con la aplicación de salvaguardias y se fomentó las exportaciones no petroleras, con lo que se pudo enfrentar la crisis petrolera que afectó a la economía del país.

El proceso de industrialización del país ha avanzado muy lentamente, el gobierno en agosto de 2016 propuso el objetivo de que las industrias representen el $25 \%$ en relación al PIB; esto está proyectado para el año 2025, en los datos obtenidos del 2007 este indicador estaba en el $13,7 \%$ y en el 2016 esté bajo a 12,6\%, es decir que aún falta mucho para dinamizar el sector industrial y por ende las exportaciones con un producto con mayor valor agregado que pueda competir internacionalmente, en si el cambio de la matriz productiva no tuvo gran influencia en el superávit que presentó la balanza comercial en el 2016 pero por lo menos logro estabilizarla para que no exista un excedente en la salida de divisas del país protegiendo la producción nacional, hay que tener en cuenta que no se han producido variaciones importantes en los productos que se exportan, no han surgido nuevos productos que pueda reemplazar la dependencia que se ha tenido a lo largo de los años del petróleo y que puedan transformar el modelo primario exportador del país.

Entonces se concluye que entre los periodos 2013 y 2016, el país ha fortalecido su presencia en el mercado internacional en ciertos sectores como por ejemplo el banano y plátano con el $24 \%$ de participación del total de exportaciones no petroleras, los enlatados de pescado los cuales generan empleo y solo codiciados por las técnicas de explotación sustentable que han venido aplicando, el sector del cacao ha ganado un gran renombre en el exterior por su identidad y calidad; la matriz productiva ha cambiado la estructura productiva del Ecuador, pero los resultados empezarán a ser más notorios a largo plazo.

\section{Referencias Bibliográficas}

Banco Central del Ecuado. (2014). Evolucion de la valanza comercial (Inf. Téc.). Quito.

El Universo. (2015). Caída del precio del petróleo entre noticias económicas del 2015 | Economía | Noticias | El Universo. Descargado 2017-10-16, de http: / / www.eluniverso.com/noticias/2015/ $12 / 18 /$ nota/5303736/caida-precio -petroleo-noticias-economicas-2015

OEC. (2017). Ecuado (ecu) exportaciones, importaciones y socios comerciales. Descargado 2017-0112, de http://atlas.media.mit.edu/es/ profile/country/ecu/
SENPLADES. (2012). Transformación de la Matriz Productiva. Revolución productiva a través del conocimiento y el talento humano (Inf. Téc.). Quito. Descargado de http://www.planificacion.gob.ec/ wp-content/uploads/downloads/2013/ $01 /$ matriz_productiva_WEBtodo.pdf

Villavicencio, A. (2016). El cambio de la matriz productiva o la mayor estafa política de la historia. Descargado de http://www .planv.com.ec/historias/sociedad/ el-cambio-la-matriz-productiva-o-la -mayor-estafa-politica-la-historia ?nopaging=1

Recibido: 16 de septiembre de 2017

Aceptado: 12 de octubre de 2017 
